\title{
Utility, Value, and Benefits of Contemporary Personal Health Records: Integrative Review and Conceptual Synthesis
}

Umar Ruhi ${ }^{1}$, BSc, MBA, PhD; Ritesh Chugh ${ }^{2}$, GCTertEd, GDInfSys, MInfSys, PhD

${ }^{1}$ Telfer School of Management, University of Ottawa, Ottawa, ON, Canada

${ }^{2}$ School of Engineering \& Technology, Central Queensland University, Melbourne, Australia

\section{Corresponding Author:}

Umar Ruhi, BSc, MBA, PhD

Telfer School of Management

University of Ottawa

55 Laurier Ave East

Ottawa, ON, K1N 6N5

Canada

Phone: 16135625800 ext 1990

Email: umar.ruhi@uottawa.ca

\section{Abstract}

Background: Contemporary personal health record (PHR) technologies offer a useful platform for individuals to maintain a lifelong record of personally reported and clinically sourced data from various points of medical care.

Objective: This paper presents an integrative review and synthesis of the extant literature on PHRs. This review draws upon multiple lenses of analysis and deliberates value perspectives of PHRs at the product, consumer, and industry levels.

Methods: Academic databases were searched using multiple keywords related to PHRs for the years 2001-2020. Three research questions were formulated and used as selection criteria in our review of the extant literature relevant to our study.

Results: We offer a high-level functional utility model of PHR features and functions. We also conceptualize a consumer value framework of PHRs, highlighting the applications of these technologies across various health care delivery activities. Finally, we provide a summary of the benefits of PHRs for various health care constituents, including consumers, providers, payors, and public health agencies.

Conclusions: PHR products offer a myriad of content-, connectivity-, and collaboration-based features and functions for their users. Although consumers benefit from the tools provided by PHR technologies, their overall value extends across the constituents of the health care delivery chain. Despite advances in technology, our literature review identifies a shortfall in the research addressing consumer value enabled by PHR tools. In addition to scholars and researchers, our literature review and proposed framework may be especially helpful for value analysis committees in the health care sector that are commissioned for the appraisal of innovative health information technologies such as PHRs.

(J Med Internet Res 2021;23(4):e26877) doi: 10.2196/26877

\section{KEYWORDS}

electronic personal health records; PHR; functionality synopsis; value analysis; consumer health informatics

\section{Introduction}

Among the many technology applications available to individuals today for managing their own health and wellness, electronic personal health records (PHRs) offer a valuable means to facilitate active participation of health care consumers, including patients and their caregivers. By virtue of their potential capabilities to help individuals track their health conditions, provide access to patient medical record information (PMRI), and offer communication tools to interact with health care providers, PHRs have been regarded as a paradigm shift toward consumer-centric and patient-oriented health and medical services [1,2].

Although the consumer adoption of PHR systems has been slower than originally expected $[3,4]$, these technologies are gaining traction in many countries worldwide [5-9]. Government eHealth initiatives in many countries are currently focused on the implementation of these technologies to foster greater patient engagement with personal health information (PHI) management and care coordination. An example of such an initiative is the 
Stage 3 Meaningful Use program under the US Health Information Technology for Economic and Clinical Health initiative. This program calls for improving patient engagement through functionality, such as patient access to medical records, patient communication tools, and interoperability with hospital electronic health records (EHRs) [10,11]. Across the border, in Canada, several federally funded projects sponsored by the Canada Health Infoway are also geared toward the deployment of consumer-focused digital health technologies, including patient health information records, patient-physician communication tools, and remote patient monitoring [12]. Along similar lines, the p-medicine and eHealthMonitor projects funded by the European Union also aim to support personalized medicine through technologies such as PHRs [7].

The overarching vision behind PHR technology offerings is to enable patient empowerment, reduce health care costs, and provide better continuity of care [3] through access to timely, reliable, and comprehensible health information for patients and streamlined communication between patients and health care providers $[13,14]$. The objective of this paper is to offer a review of the utility, value, and benefits of PHR systems through a discussion of their features and functions and to deliberate how PHR functionality can potentially translate into value for the health care consumer and benefits for the health care system as a whole. Our review comprises both an analysis and a synthesis-oriented exposition on the current landscape of PHR technologies. The Methods section outlines our review approach and the ensuing structure of this study.

\section{Methods}

\section{Overview}

In characterizing the type of review offered in this paper, our discussion aligns with an integrative review, in which literature pertinent to a subject area is critically analyzed and synthesized to theorize alternative perspectives of the subject [15]. Although integrative literature reviews may serve multiple purposes, their essence is to review existing literature to elicit new insights, inquiries, or answers through the integration and synthesis of existing literature [16]. Integrative reviews are commonly used in health research [17-19], and such reviews have been purported to enhance the development of health care theory, policy, and practice [19]. Our integrative review was structured along the following 5 recommended phases [19]: problem identification, literature search, data evaluation, data analysis, and presentation of the results. The procedures followed are summarized below.

\section{Problem Identification}

Specific to our study, the purpose of our review is to extensively research pertinent PHR literature and provide an assessment of the product utility, consumer value, and industry benefits of these systems. Toward this, and in line with integrative reviews, we developed a protocol for the search and selection of relevant literature $[15,16]$, deliberated the capabilities of PHR systems using several lenses of analysis, and then classified and synthesized a typology to formulate conceptual frameworks that explicate the utility and value of PHR systems. Typologies that offer a conceptual classification of constructs are recommended as useful theory-building tools [20] and a valuable form of synthesis in integrative reviews [15].

To guide our review process, we formulated 3 research questions that we aimed to answer through our analysis and synthesis of the extant literature. Table 1 below is the three-step approach that we adapted for our review based on suggested guidelines for the reviews of emerging HITs [21,22]. The Results section of this paper discusses the findings and outcomes from our review, as noted in Table 1.

Table 1. Research questions and guidelines followed for the review and synthesis.

\begin{tabular}{|c|c|c|c|}
\hline $\begin{array}{l}\text { Review perspec- } \\
\text { tive }\end{array}$ & $\mathrm{RQ}^{\mathrm{a}}$ & HIT $^{\mathrm{b}}$ assessment review guidelines & Review and synthesis outcomes \\
\hline Product utility & $\begin{array}{l}\text { RQ1. What features and functions are available in } \\
\text { contemporary PHRs }{ }^{c} \text {, and how has this functionality } \\
\text { evolved over time? }\end{array}$ & $\begin{array}{l}\text { 1. Technology definition and litera- } \\
\text { ture search }\end{array}$ & $\begin{array}{ll}\text { - } & \text { Literature selection procedure } \\
\text { - } & \text { PHR working definition } \\
\text { - } & \text { Functional utility model of } \\
\text { PHR technologies }\end{array}$ \\
\hline Industry benefits & $\begin{array}{l}\text { RQ3. How can the mainstream deployment and use } \\
\text { of PHR systems translate into benefits for the health } \\
\text { care system as a whole? }\end{array}$ & 3. Reflective synthesis and summary & $\begin{array}{l}\text { - Value propositions and bene- } \\
\text { fits of PHR systems }\end{array}$ \\
\hline
\end{tabular}

${ }^{\mathrm{a}} \mathrm{RQ}$ : research question.

${ }^{\mathrm{b}}$ HIT: health information technology.

${ }^{\mathrm{c}}$ PHR: personal health record.

\section{Search Strategy}

Our academic article search was conducted using digital library databases, including PubMed, Web of Science, ScienceDirect, and Scopus. In addition, to ensure the breadth and validity of our search results, we explored the publications cited in previous scoping and systematic reviews of PHRs [23-25] and included any relevant articles that had been overlooked in our own search. 
Our search techniques used various terms and keywords related to PHRs, including acronyms as well as expanded terms, such as PHR, personal health record, EPHR (electronic personal health record), patient portal, personal medical record, personally controlled health record, PCHR, personal health information, and PHI.

\section{Data Evaluation}

Both authors independently screened titles, keywords, and abstracts to determine whether publications should be included in the review. Our review included studies that explicitly discussed features, functions, utility, value, and benefits of electronic PHRs, whereas it excluded publications focusing on paper-based PHRs or studies solely focusing on psychosocial aspects of end users' PHR adoption or technical system design practices for PHRs. Following the first round of screening, we refined our search criteria and examined articles pertaining to consumer health informatics as a general field of study. Our initial review indicated that some publications pertaining to consumer health informatics directly discuss the benefits of PHR technologies [13,26-30]. In the second round of screening, each author assessed mutually exclusive but collectively exhaustive subsets of all publications identified as potentially relevant, and we ensured that the articles were indeed pertinent to our review.

\section{Data Analysis and Synthesis}

Following the selection of relevant literature, our review process began with an iterative concept-centric analysis of the attributes and benefits of PHR systems. We analyzed the literature at the product level by identifying various features and functions of PHR systems described in the extant literature, at the consumer level by deliberating the value of various PHR system functionalities, and at the industry level by identifying the benefits provided by PHR technologies to various health care industry constituents. A codebook was created to facilitate the analysis and extraction of data into systematic categories. The authors collaborated on the conceptual synthesis of the 3 classification systems for functional utility, consumer value, and industry benefits. These conceptual classifications were refined iteratively through simplification, abstraction, and focusing procedures, constituting the constant comparison method commonly recommended for integrative reviews [19].

\section{Presentation and Paper Structure}

In the final phase of the integrative review, the results from our analysis and synthesis were summarized and depicted using visual models and concept matrices. These are presented and discussed in the Results section of this paper.

We first provide a working definition of PHRs that was used as a touchstone to guide our literature search and subsequent discussion. Drawing upon that definition, we retrieved relevant peer-reviewed publications and industry reports that discussed the functionality, utility, value, and benefits of PHR technologies.

The outcome of our review of PHRs from a product utility perspective comprised an evaluation of various features and functions of PHR systems. The output from this evaluation is conceptualized as a high-level functional model of PHRs that summarizes the myriad of features and functions available in contemporary PHR systems.

Next, we discuss the capabilities of PHR systems from a consumer value orientation by juxtaposing the functionality of PHR systems alongside health care delivery activities ranging from prevention to the diagnosis and ongoing management of illnesses.

Finally, the Results section provides an industry-level viewpoint that summarizes various value propositions and benefits related to the use of PHR technologies at the micro, meso, and macro levels. The synthesis offers a discussion of how the effective deployment and use of PHR technologies can potentially translate into benefits for different constituents in the health care delivery chain, including consumers, providers, payors, and public health agencies.

\section{Results}

\section{Defining Characteristics of PHRs}

As a working definition, this paper adopts one of the earliest and most commonly cited characterization of a PHR as "an electronic application through which individuals can access, manage and share their health information and that of others for whom they are authorized, in a private, secure and confidential environment" [31]. In addition, PHR are sometimes referred to as personally controlled health records (PCHRs) comprising information and communication technologies that can potentially help all types of end users in maintaining health and wellness and specifically facilitate patients in managing their ongoing illnesses [32].

To further delineate the representative attributes of PHRs, we also differentiate between 3 similar yet distinct technologies related to patient records: electronic medical records (EMRs), EHRs, and PHRs. Depending on the health care setting, although these 3 technologies may be used as components in an integrated health information system (HIS), each of them can be differentiated from the other based on its custodianship and level of patient centricity. EMRs are often considered as digital versions of paper charts in a clinician's office [33]. These patient medical records in this instance are provider-centric [33,34] and are rarely accessible to other health care providers or to the patients themselves. In contrast, EHR systems offer a broader view of a patient's care by facilitating integration with HIS beyond the organization that originally collected and compiled the patient information [33]. These systems can aggregate patient data from multiple health care facilities to create a unified patient record that can be accessed by health care providers $[35,36]$. Finally, PHRs function under the custodianship of patients or their caregivers, and these systems comprise full or partial health information about patients over their lifetime $[35,37]$. Hence, PHRs specifically pertain to digitally stored health care information about an individual patient under the control of that patient or their caregiver [7,38], whereas EMRs and EHRs are typically maintained by health care providers or payor organizations [39]. 
Drawing upon these characteristics of PHR systems, this study adopts a consumer-oriented perspective and uses the term PHR to refer to both the underlying patient record and its data elements as well as the software that provides functionality to maintain that record. As such, we do not differentiate between the data (PHR) and PHR-S (software components of PHR), as sometimes done in the industry standard documentation such as HL7 (Health Level Seven) [40,41]. Furthermore, although we note that there may be differences among PHR systems in terms of front-end technology features, back-end information sources, patients' scope of access, and storage locations of online records, we consider electronic access (desktop, web, or mobile) and patient control over health records to be the defining characteristics of PHR systems.

To help understand the functional scope of the current PHR systems, researchers have classified these technologies into 3 main categories: standalone, tethered, and interconnected $[32,37]$. The main attributes that differentiate these categories are data control, record portability, and system interoperability. The key differences among these categories are outlined below.

Standalone PHRs require users to manually enter data to populate their own health information and medical history. Hence, the content of these applications is under direct physical control and ownership of the consumer. These PHR systems require a considerable long-term commitment from end users who need to be motivated to maintain their PHI in an accurate and complete fashion $[37,42]$. Although these technologies may be portable in allowing users to access their PHI anytime and anywhere, they lack interoperability because data must be manually imported or exported from other HIS.

Tethered PHR systems are typically offered as extensions of a health care institution's own back-end EHR or EMR system, providing users access to parts of their own EHRs. These systems are also referred to as patient portals. In addition to providing access to patient data, these systems may also include additional functionality, such as communication tools for email, messaging, appointment scheduling, and prescription renewals [37]. Access to these PHRs is typically provided through a web portal interface $[32,43]$. The data in tethered PHR systems are under the control of the health care provider, hence limiting the portability of patient records, and these technologies may not be fully interoperable with other HIS.

Interconnected PHRs are often described as the ideal or preferred type of PHR in terms of data control, record portability, and system interoperability [7,37,44,45]. These systems can usually be populated with patient information from a variety of sources, including physician EMRs, hospital EHRs, insurance carriers, health plan sponsors, labs, and pharmacies $[29,37]$. In addition, users can enter their own information in the selected areas of the PHR. These PHR systems offer consumers adequate control over parts of their health records and also alleviate the need for manual data entry. In addition, because of the established electronic linkages among some HIS, records can usually be easily transferred from one provider to another. Despite the limited offerings in this space, the functionality of these integrated systems is expected to translate into a wider range of convenience benefits and improved health outcomes for consumers as well as operational efficiencies for providers.

\section{Product Utility of PHR Systems}

On the basis of the discussion above on different types of PHR systems, one may be led to believe that tethered or interconnected PHRs offer considerably advanced functionality in comparison with standalone PHR systems. Although this is certainly true in the context of system capabilities that require back-end integration with provider EMR or EHR systems, there may be a range of other PHR features and functions that do not depend on such integration, and these can be offered through stand-alone PHRs just as well. For example, certain stand-alone PHR products provide a deeper functionality related to health resource libraries, patient-centered health monitoring, and linkages with web-based support groups-features that do not necessarily need high levels of system interoperability with other HIS.

In this section, we draw upon the extant academic literature as well as the current industry PHR software offerings to provide an overview of various functionalities that may be available in contemporary PHR systems. To aid our discussion, we organize the different PHR capabilities into different categories based on the consumers' modalities of use and functional characteristics of system features and functions. Figure 1 depicts the conceptualization of a high-level functional utility model of PHR systems. The elements of the model are briefly described below. It should be noted that our model does not aim to provide a system specification or technical architecture of PHR systems. These have been described elsewhere in the extant literature $[30,45,46]$. Our model simply aims to provide a scaffold to aid a high-level understanding of PHR systems at the consumer level. 
Figure 1. A high-level functional utility model of personal health record systems.

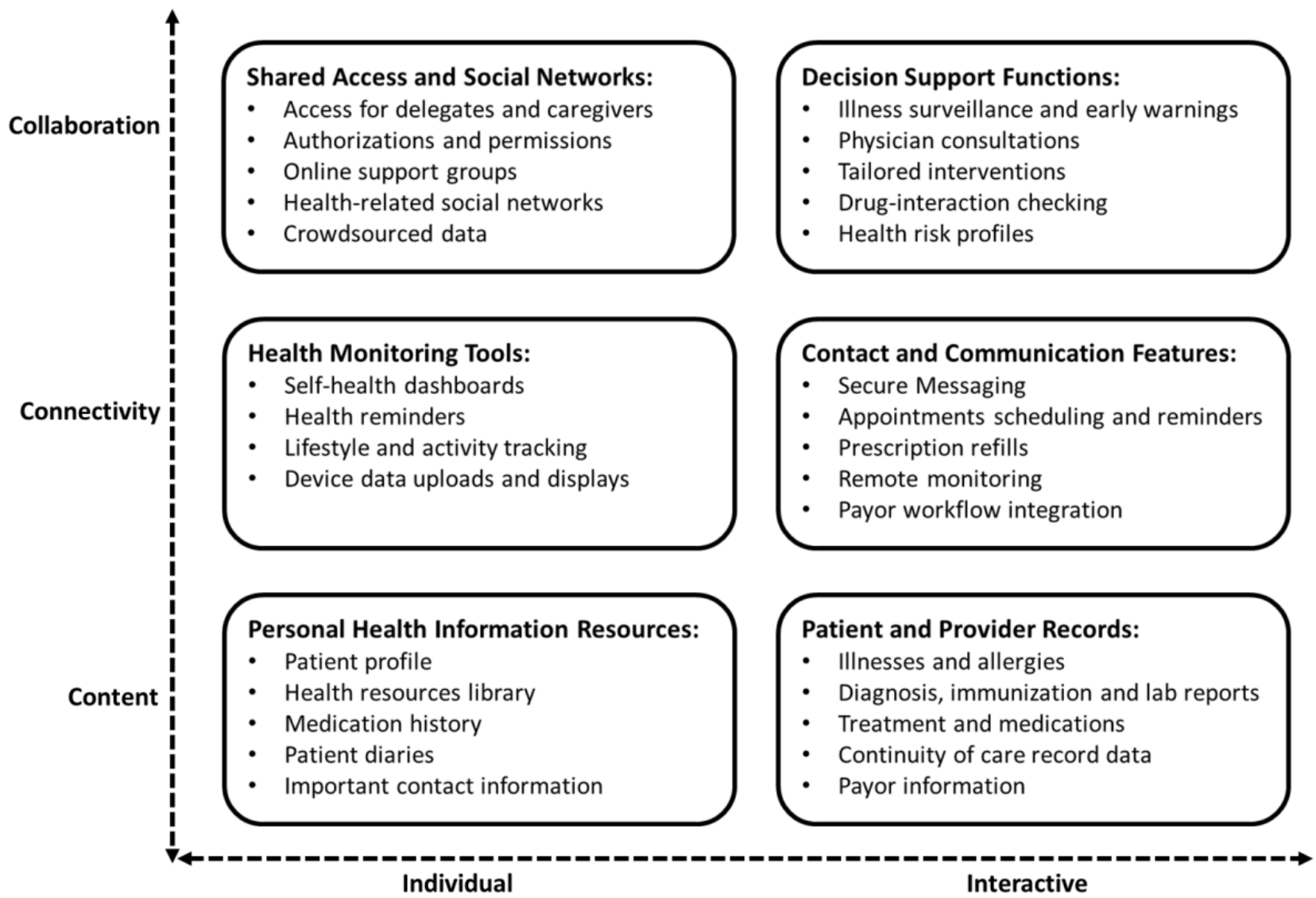

In terms of modalities of use, our model differentiates between the individual and interactive modes of using PHR functions. Although individual modes of use entail highly personalized user-initiated tasks, interactive modes usually comprise bidirectional exchanges between the consumer and other care delivery constituents, including physicians, providers, or payors. Most of the individual tasks are performed in an asynchronous style with frequent individual interventions, whereas interactive exchanges usually occur in a dynamic and synchronous fashion.

Our model also characterizes PHR functions as being primarily content-, connectivity-, or collaboration-oriented. Content-rich features refer to PHR technologies that are primarily used for information management. Information can be pushed automatically or retrieved on an as-needed basis or it can be maintained within the PHR by users on their own. In connectivity-based applications, information is exchanged, and transactions are conducted in a 2-way flow between applications, devices, organizations, or people. Finally, collaboration-based mechanisms subsume other functional modes and offer tools for interpersonal exchanges and decision support, thereby enabling consumers to proactively manage their health and wellness. On the basis of these criteria for classification, we categorized various PHR features and functions into 6 groups: PHI resources, patient and provider records, health monitoring tools, contact and communication features, shared access and social networks, and decision support functions.

\section{PHI Resources}

At their core, most PHR systems comprise a repository of PHI that allows consumers to maintain their own profiles and medical history data. Various tools such as digital diaries to manage the lists of drugs and track personal data such as weight, glucose, and cholesterol levels allow consumers to exercise control over their medical information [47-49]. Additional functionality with links to web-based health information can help consumers create a library of health information resources pertinent to them [50,51].

\section{Patient and Provider Records}

For PHRs with electronic links to other HIS from providers, pertinent PMRI can be seamlessly added to the PHR system. Data from patient diagnosis, treatments, and medications can be added from physicians' EMRs or providers' EHR systems [50,52-57]. Patient health summary standards such as the CCR (continuity of care record) can provide guidelines for PHR pertinent data that would provide a holistic view of patient care and consequently improve the portability of patient health information [42,55,58].

\section{Health Monitoring Tools}

Beyond self-managed health information, many PHR technologies also facilitate connectivity with a range of medical and lifestyle tracking devices. Data from these devices can be uploaded to PHRs to enable consumers to keep track of their health and wellness [55,56,59-62]. In addition, these behavior management tools can help consumers track their health indicators via a dashboard style interface and also set up various notifications and alerts for any anomalies or items that require their attention [63-65]. 


\section{Contact and Communication Features}

The tools in this category are considered extremely useful by consumers for interconnected PHRs linked to provider EMR and EHR systems [7,45,52,59,60,64]. Although features such as patient-physician and patient-provider secure messaging and appointment scheduling provide convenience to users, other tools for prescription refills and insurance claims processing can help streamline process workflows for all constituents in health care delivery [66-68]. Advanced PHR offerings also provide telehealth features for patients to provide the results of basic health assessments from home and to transfer data from connected medical devices [37,64,69].

\section{Shared Access and Social Networks}

Most PHR systems provide a core set of collaboration tools to help consumers share their health information with other authorized people, including caregivers and designated family members. They do so by delegating access rights and permissions to the specific parts of their PHR [37,64,69]. More recently, social networking tools have been integrated with some PHRs to provide patients with more access to information from practitioners as well as from other patients with similar medical conditions $[29,70]$. The range of possibilities for social networking features in PHR offerings span a wide spectrum from basic moderated health discussion forums for questions and answers [59] to sophisticated sites that crowdsource patient data from connected devices to foster an active dialog among patients or to contribute to further research about illnesses [71].

\section{Decision Support Functions}

In interconnected PHR systems, collaborative interactions between patients and clinicians can be enabled through decision support features that include illness surveillance, virtual consultations, and computerized tailored interventions [29,72]. In addition, rule-based engines can also provide input to the decision-making processes through tools such as patient health risk profiles and drug-interaction checking [7,73-75]. By using patient data from other parts of the PHR and leveraging practitioner expertise, such tools can help in evaluating the harms and benefits of specific treatment options [37,63,76], issue health warnings through personalized clinical decision support (CDS) notifications [29,77], and recommend alternative treatments $[37,73,78]$. Recent studies have also shown that personalization-focused PHR functions such as tailored interventions with highly individualized communication, therapy, or medications can be extremely effective in inducing behavioral changes and improving patient health $[79,80]$.

\section{Consumer Value of PHR Systems}

Drawing upon the review of the features and functions of PHR systems at the product level, this section discusses a consumer-centric viewpoint of the potential value that might be realized through the effective use of these technologies. To facilitate this viewpoint, we appropriate the conceptual framework of the care delivery value chain (CDVC) [81-83], which offers a systematic approach to delineate and analyze health care services and activities that jointly determine the overall success of health outcomes for consumers [81]. According to the CDVC framework, the value for the health care consumer is determined by the results and outcomes rather than the inputs and volume of the range of health care services provided [84]. Using a similar reasoning, we maintain that in the case of PHRs, the consumer value is determined not by the functions and features of technologies per se but also by their potential to address the needs, expectations, and preferences of consumers during the various health care delivery activities. The CDVC classifies these activities into 6 main areas: prevention, diagnosis, preparation, interventions, recovery, and ongoing management of illnesses [82,83].

Figure 2 presents a visual depiction of our conceptualization of the PHR consumer value framework that juxtaposes various PHR features and functions (described in the Decision Support Functions section) alongside the CDVC-defined 6 core activities in the health care delivery value chain. The relationships between PHR functionality and health care activities are depicted as lightly or darkly shaded intersections. The latter represents a high (direct) alignment or mapping between specific PHR functionality and health care delivery activity, as evidenced by strong support in the extant literature. To determine the strength of mapping between PHR functional categories and CDVC activities, we identified different use cases for PHR features and functions from the extant literature. These use cases are listed in Multimedia Appendix 1, which serves as a foundation for the summary depicted in Figure 2. A brief overview of the applications of PHR functionalities in different health care delivery activities is provided below. 
Figure 2. Personal health record consumer value: a mapping of personal health record functionality to the health care delivery value chain. PHR: personal health record.

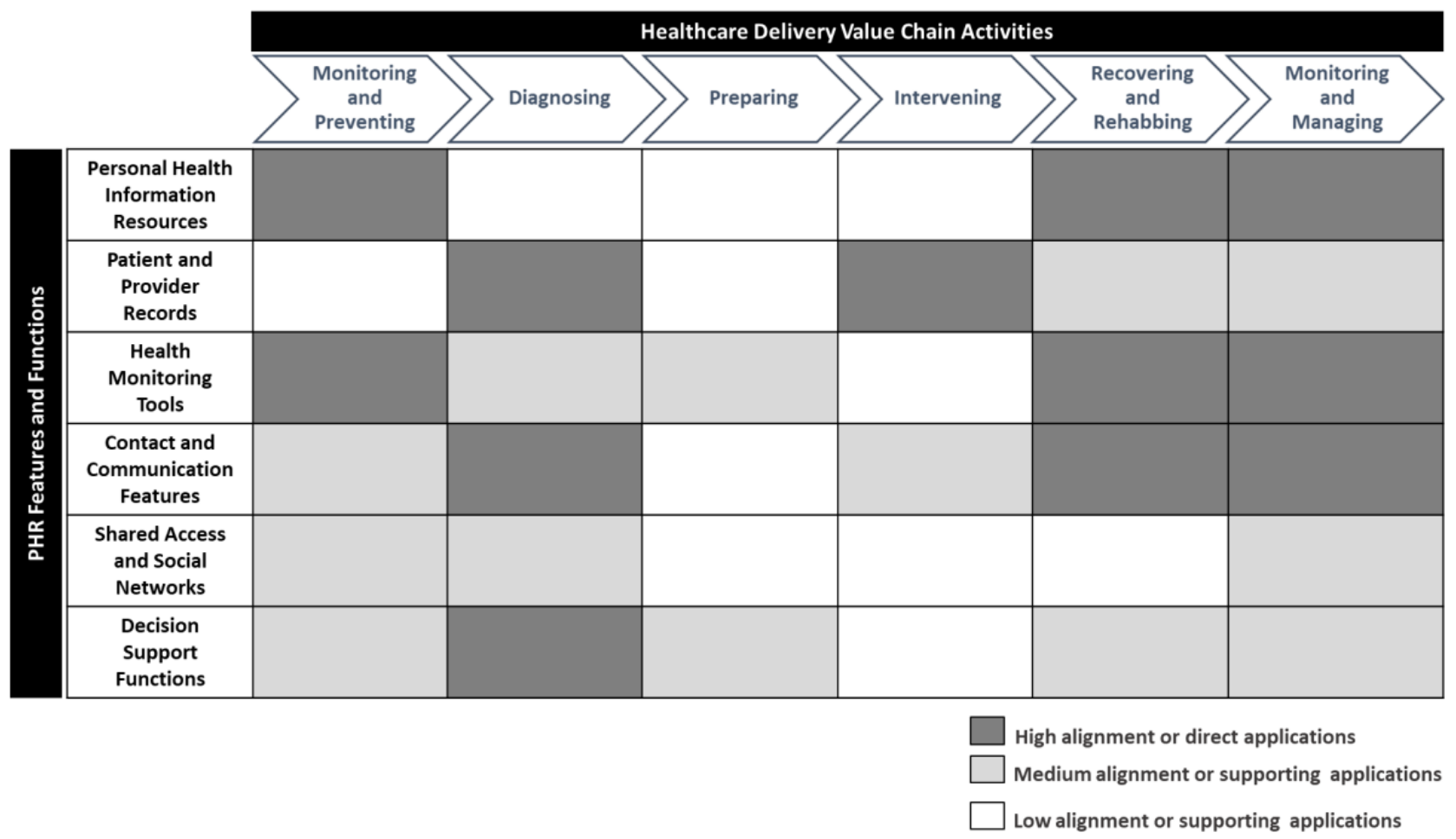

\section{Monitoring and Preventing}

These activities are primarily concerned with tracking an individual's current conditions and assessing health risks to proactively prevent or reduce the seriousness of illness or injury [81]. Comprehensive patient profile and medical history information sourced from personally reported data as well as patient clinical records can directly help in the early detection of illnesses or reducing the need for medical treatments $[7,48]$. Furthermore, the integrated use of health devices and self-management dashboards can help track lifestyle-or illness-related risk factors such as diet patterns, blood pressure, and glucose levels, which can help support preventive health care activities $[48,55,59,85,86]$. Social networks can also help support the proactive posture of patients by helping source relevant information about health conditions and treatments from practitioners and other patients [29,71]. Decision support tools offer an additional functionality to help with the proactive detection and resolution of potentially threatening health conditions through CDS advisories and virtual counseling from experts about potential future health risks [55,74,75,81].

\section{Diagnosing}

Diagnosing activities in the care cycle comprise a range of processes, such as laboratory testing, medical history evaluation, consultations with specialists, and the formulation of treatment plans. As depicted in Figure 2, there is a strong support in the extant literature that multiple PHR functionality groups have direct or indirect applications in diagnosis-related care activities. The ready availability of PMRI in interconnected PHR systems can help facilitate these activities $[47,52,53,70]$. These activities can also be enabled through decision support tools, such as virtual physician consultations and computerized tailored interventions [29,55,70,75]. Finally, in terms of supporting functionalities, personally tracked and self-reported personal information and family medical history shared through the PHR can also help in improving the overall quality of diagnostic processes [47,55,70,75,87].

\section{Preparing}

These activities refer to all setup procedures and processes that need to be completed before medical intervention. In the original CDVC framework, the authors note that this set of activities is often overlooked in the health care system $[81,82]$. Perhaps this is why our review also yielded very little direct evidence of PHR applications in this area. Nonetheless, we believe that PHR functionality related to health monitoring tools and decision support functions can help in supporting such preparatory activities. The former can help with the tracking of important health data from lifestyle health data dashboards and connected medical devices $[61,62,65]$, whereas the latter can facilitate reviews of health profiles, interactions with specialists, and verification of potential drug interactions $[29,73]$.

\section{Intervening}

Intervention processes and procedures are targeted at reversing or mitigating a health condition [81], and they typically include the initiation of therapy, treatment, or medication and the management of potential infections or associated illnesses. PHRs can play an important role in improving the quality of medical interventions by providing up-to-date medical history and PMRI across various points of care and by facilitating continuity of care $[42,54,66,68]$. In addition, contact and communication features in PHR systems can help patients receive regular and situational counseling on treatment and prognosis and can help attending physicians ensure treatment compliance $[81,83]$. 


\section{Recovering and Rehabbing}

These services are an essential component of care for all medical conditions [81], and the procedures are important for ensuring effective recovery and positive health outcomes for patients in the long term. PHR systems can help in achieving these health outcomes through an improved health monitoring of risk factors and lifestyle data [55-57,61,65,86,88,89] and by seamlessly connecting patients to providers for referrals, follow-ups, and prescription refills [63]. These features are also complemented well by decision support functions that can facilitate the development of tailored interventions and help in tracking and resolving treatment side effects $[62,73,75,90]$.

\section{Monitoring and Managing}

Activities that constitute the final part of the care delivery chain aim to manage patient conditions and monitor therapy compliance on an ongoing basis [83]. As shown in Figure 2, PHI resources, health monitoring tools, and contact and communication features can potentially play a significant role in enabling these monitoring and managing activities [56,57,85,89,91,92]. Multiple studies pertaining to chronically ill patients using PHR technologies have demonstrated the usefulness of features such as personal logs and links to educational resources as well as tools such as web-based appointment scheduling, meeting reminders, and email communication with health care professionals [85,91,93]. Together, these tools can play a vital role in minimizing long-term health risks related to chronic illnesses [56,57,82,89,92].

Overall, the effective deployment and adoption of PHRs can potentially enable improved integration across health care activities that constitute the full cycle of care for a consumer. Such integration across the entire chain has been posited as the major driver of health care consumer value [83].

Our analytical framework highlights the similarities and complementarities among various PHR functions and features by conceptualizing the direct and supporting applications of PHRs in different health care activities. Furthermore, a circumspect inspection of the framework shows that the consumer value from contemporary PHRs primarily relates to care activities with a proactive health management orientation. Monitoring activities at the beginning and end of the care delivery chain has a high number of associated PHR applications, followed by activities related to diagnosis and recovery. From the viewpoint of various PHR functional categories, contact and communication features appear to have the most recurrent use cases, followed by personally and clinically sourced health record information as well as health monitoring tools. Our analysis supports previous research that indicates that PHR users consider connectivity features that facilitate health care processes to be the most useful tools [48,94].

\section{Industry Benefits of PHR Systems}

Having discussed the functionality of PHR systems and their applications in various health care activities, this section of the paper offers a summary of the benefits of PHR systems for the health care industry. In deliberating these benefits, we underscore our assertion that the value-producing potential of PHRs is not only dependent on the adoption of these technologies by consumers but also on the active participation for the provision and use of these technologies by multiple health care delivery constituents, such as hospitals, labs, pharmacies, insurance companies, and government agencies. Consequently, the effective deployment and adoption of PHRs can result in a variety of benefits for these constituents [95].

The lens of analysis used to outline the industry benefits of PHRs is based on an extension of the health care value chain described in the Monitoring and Managing section. However, rather than focusing on care delivery activities, we adopt a channel partner perspective and highlight the benefits of PHR technologies to various entities that comprise the health care system. Using standard health care industry nomenclature $[96,97]$, we refer to providers as any clinicians, allied health professionals, or organizations that render direct health care services to consumers; payors as entities that finance the cost of health services (eg, insurance carriers or health plan sponsors); and public health agencies as government institutions concerned with research and policy issues for the social well-being of communities as a whole [97].

Table 2 offers a review summary of the industry benefits of PHRs by outlining the core value propositions and the principal benefits of these technologies to different constituents. Value propositions pertain to micro-level benefits for consumers, meso-level benefits for providers and payors, and macro-level benefits in the realm of public health. These are briefly discussed herewith. 
Table 2. Value propositions and benefits of personal health record systems to health care delivery constituents.

\begin{tabular}{lll}
\hline Value propositions and benefits & Literature support & Health care delivery constituents \\
& Consumers Providers Payors Public \\
health & & agencies
\end{tabular}

Consumer empowerment and patient engagement

Promote consumer health education

Enable patients to become informed health care consumers

Enhance understanding of medical conditions

Simplify and clarify patient instructions

Provide a greater control over health outcomes

Offer convenient self-health management

Facilitate self-efficacy via cues for patient action

\section{Health care communication}

Improve patient-physician or provider communication

Timely information sharing for clinical decisions

End-to-end care delivery involving multiple constituents

\section{Process efficiencies and cost effectiveness}

$[5,42,44,66,98]$

$[29,42,57,66,74,75,99,100]$

$[29,42,57,66,74,75,99,100]$

$[3,56,101,102]$

$[21,56,68,86,89,103,104]$

$[13,102]$

$[14,42,105]$

$[68,85,90,103]$

$[44,55,68,89,106,107]$
$[14,50,57,68,76]$
Increased portability of patient records

Reduced cost of chronic disease management

Greater medical information validity and accuracy

Save patient, physician, and provider time

Reduced cost of duplication of tests and procedures

\section{Enhanced quality of care}

Increased patient safety considerations

Improved handling of emergency situations

Extended durability of patient data

[44,57,63,68,89,108,109]

$$
[32,110]
$$

$[42,59,75,76,111,112]$

$[14,32,57,85]$

$[42,59,113]$

[90,103,114]

[115,116]

[32,104,109]

$[76,115,117,118]$

Early identification of patient risks and health susceptibilities

\section{Public health outcomes}

Reduced burden on health care system and resources

Enhanced care for underserved communities and populations

Facilitate care in public health emergencies

[119,120]

Support public health research

New avenues for epidemiology surveillance and screenings
$[3,55,59,63]$

$[3,59,63,95]$

$[71,90,121,122]$

${ }^{\mathrm{a}}$ Mapping of value propositions and benefits of personal health records to various health care delivery constituents.

\section{Consumers}

From the perspective of consumers, PHR users are not only likely to be better informed about their health conditions $[5,63,123]$, but they also actively participate and increasingly contribute toward their own health management activities [57,102]. PHRs have the potential to provide patients with a better understanding of health information and clearer health care instructions [74,100]. PHRs can also assist users in monitoring daily self-care activities and enable patients to collaborate and share their experiences with their providers and caregivers. As an integrated patient-centered technology, PHRs also offer the means for increased patient engagement through improved provider-patient and physician-patient communication $[14,54,66,68,74]$, thus leading to greater personalization of care [3]. 


\section{Providers}

From the perspective of providers, a primary benefit of PHR systems is that these technologies address a significant gap in the current health information exchange mechanisms. In the absence of stable and formal technology standards that allow the transfer of patient records from one provider to another, PHRs can offer an alternative means to achieve this purpose [44,63,107]. Patients can access their health records as, when, and where needed. PHR systems can also help reduce health care costs and inefficiencies, especially those associated with inaccurate information and effort duplication [42,57,59,113]. Patients can directly verify health data, and a complete access to patient history from across providers can assist in avoiding unnecessary laboratory tests and medical procedures.

\section{Payors}

Providers and payors can also benefit from the patient adoption of PHRs because the use of these systems is likely to improve patient safety through an early identification of health risks $[76,90,103,114]$, reduce the cost of chronic disease management $[32,110]$, and enable health care institutions to better handle emergency situations [115,116]. Access to unified PMRI across health care providers can help alleviate medical treatment disruptions for patients with chronic conditions [124], and features such as remote monitoring and eHealth consultations can enable earlier and efficient hospital discharge and long-term patient monitoring processes [64,69].

\section{Public Health Agencies}

From the viewpoint of public health agencies at a macro level, the mainstream adoption of PHRs can lead to a variety of benefits for population health [95]. These technologies can help in reducing health care disparities across demographic, economic, and regional divides, and these technologies offer a means of access to high-quality health care for all [124]. By helping overcome structural barriers to quality health care, PHR technologies can potentially improve the health status of underserved communities and populations $[69,124]$. From a cost perspective, proactive care delivery made possible through these technologies can help in reducing the burden on public health institutions and resources $[3,59,63,76]$.

Finally, from a population health research standpoint, consumer consent to sharing health care information and the subsequent widescale accumulation of PHR data have the potential to act as a valuable source of public health information for promoting healthy lifestyles and for detecting and preventing infectious diseases [119]. Through appropriate privacy and consent mechanisms, patient data available through an integrated health care network can be used to facilitate public health research on individuals and their communities as well as help with regional and global illness surveillance and screenings [55,90,121].

Overall, PHR systems can play a transformative role in facilitating complex information management processes across various health care delivery constituents. The mainstream deployment and adoption of these technologies has the potential to improve clinical and population health outcomes by streamlining medical and operational processes across the health care system.

\section{Discussion}

Although several previous studies on PHR technologies have alluded to a distinction among the functionality, utility, and value of these technologies [5,47,125], our review of the literature did not reveal any formal treatise of this subject at a theoretical or an empirical level. Our study aims to address this gap through a review and synthesis of the literature.

This paper presents a review of the extant literature on PHR systems, with the objective of providing an overall assessment of the functionality, utility, value, and benefits of contemporary PHRs. Toward this end, we offer a conceptual high-level functional utility model of PHRs outlining their features and functions categorized according to different use modalities. In addition, we deliberate on the value of PHR technologies to consumers by highlighting their applications across the spectrum of health care delivery activities. Finally, we provide a holistic summary of the value propositions and benefits of PHR systems to various health care industry constituents, including consumers, providers, payors, and public health agencies.

Our review indicates that PHR systems have made considerable progress over the past decade in terms of technology features and functions available at the product level. Compared with early PHR products that simply offer a basic functionality to maintain PHI [47,70], contemporary technologies offer a myriad of content-, connectivity-, and collaboration-based features and functions. Consequently, in recent years, the academic community has paid increasing attention to PHR functionality related to health monitoring tools, social networking features, and CDS functions.

From a value perspective, our analysis demonstrates that the value-generating potential of PHR systems arises from their role as an enabler for the integration of health care delivery activities across the full cycle of care for the health care consumer. These technologies can offer a useful mechanism for information exchange and care coordination among providers, thus leading to improved health outcomes for consumers. The consumer value framework conceptualized in this paper highlights that PHR functions have the potential to enhance patient experience through various touchpoints in health care delivery.

Our review also shows that although consumers are the primary beneficiaries of the functionality provided by PHR technologies, their overall value and benefits span across the activities and constituents of the health care delivery chain. At the consumer level, PHR systems can facilitate improved consumer health outcomes through the self-management of health and wellness as well as through enhanced quality of care. Moreover, these technologies can also generate channel partner value for providers and payors by enabling operational efficiency and reducing the cost of care. Finally, long-term and effective use of PHRs can also produce societal value in the form of improved public health outcomes.

This study offers several opportunities for research and potential practical applications. In terms of future research directions, we encourage researchers to undertake an empirical assessment of 
our conceptualized functional utility and consumer value frameworks for PHR technologies. In particular, our literature review indicates a significant dearth of studies addressing the issue of consumer value of PHR offerings. Our study offers a possible starting point for this type of research. For health care practice, our review may be relevant to health care professionals associated with value analysis committees that are commissioned for the appraisal and recommendation of innovative HITs. A value framework such as the one proposed in this paper that integrates functional attributes, use cases, and applications in health care delivery activities can potentially be applied to the value assessment of other HITs as well.

\section{Acknowledgments}

The research reported here was supported by the Telfer School of Management Research Fund (SMRF grant) at the University of Ottawa.

\section{Conflicts of Interest}

None declared.

\section{Multimedia Appendix 1}

Examples of personal health record use cases in the health care delivery value chain.

[PDF File (Adobe PDF File), 165 KB-Multimedia Appendix 1]

\section{References}

1. Woods SS, Schwartz E, Tuepker A, Press NA, Nazi KM, Turvey CL, et al. Patient experiences with full electronic access to health records and clinical notes through the My HealtheVet Personal Health Record Pilot: qualitative study. J Med Internet Res 2013;15(3):e65 [FREE Full text] [doi: 10.2196/jmir.2356] [Medline: 23535584]

2. Young-Mason J. Information and knowledge is power: the online personal health record. Clin Nurse Spec 2013;27(2):105-106. [doi: 10.1097/NUR.0b013e3182818fea] [Medline: 23392069]

3. Greenhalgh T, Hinder S, Stramer K, Bratan T, Russell J. Adoption, non-adoption, and abandonment of a personal electronic health record: case study of HealthSpace. Br Med J 2010 Nov 16;341(nov16 1):5814 [FREE Full text] [doi: 10.1136/bmj.c5814] [Medline: 21081595]

4. Gartrell K, Storr CL, Trinkoff AM, Wilson ML, Gurses AP. Electronic personal health record use among registered nurses. Nurs Outlook 2015 May;63(3):278-287 [FREE Full text] [doi: 10.1016/j.outlook.2014.11.013] [Medline: 25982768]

5. Kahn JS, Aulakh V, Bosworth A. What it takes: characteristics of the ideal personal health record. Health Aff (Millwood) 2009 Mar;28(2):369-376 [FREE Full text] [doi: 10.1377/hlthaff.28.2.369] [Medline: 19275992]

6. Wolfson E. The personal health record. Healthline Networks Inc. URL: http://www.healthline.com/hlc/ personal-health-record?micrositeId=30 [accessed 2019-06-18]

7. Genitsaridi I, Kondylakis H, Koumakis L, Marias K, Tsiknakis M. Evaluation of personal health record systems through the lenses of EC research projects. Comput Biol Med 2015 Apr;59:175-185. [doi: 10.1016/j.compbiomed.2013.11.004] [Medline: 24315661]

8. Pinciroli F, Pagliari C. Understanding the evolving role of the personal health record. Comput Biol Med 2015 Apr;59:160-163. [doi: 10.1016/j.compbiomed.2015.02.008] [Medline: 25726437]

9. Ford EW, Hesse BW, Huerta TR. Personal health record use in the United States: forecasting future adoption levels. J Med Internet Res 2016 Mar;18(3):e73 [FREE Full text] [doi: 10.2196/jmir.4973] [Medline: 27030105]

10. Goldzweig CL. Pushing the envelope of electronic patient portals to engage patients in their care. Ann Intern Med 2012 Oct 02;157(7):525-526. [doi: 10.7326/0003-4819-157-7-201210020-00013] [Medline: 23027322]

11. Appari A, Eric JM, Anthony DL. Meaningful use of electronic health record systems and process quality of care: evidence from a panel data analysis of U.S. acute-care hospitals. Health Serv Res 2013 Apr;48(2 Pt 1):354-375 [REEE Full text] [doi: 10.1111/j.1475-6773.2012.01448.x] [Medline: 22816527]

12. Adler-Milstein J, Sarma N, Woskie LR, Jha AK. A comparison of how four countries use health IT to support care for people with chronic conditions. Health Aff (Millwood) 2014 Sep;33(9):1559-1566. [doi: 10.1377/hlthaff.2014.0424] [Medline: 25201660]

13. Demiris G. New era for the consumer health informatics research agenda. Health Sys 2017 Dec 19;1(1):13-16. [doi: 10.1057/hs.2012.7]

14. Smith AB, Odlum M, Sikka M, Bakken S, Kanter T. Patient perceptions of pre-implementation of Personal Health Records (PHRs): a qualitative study of people living with HIV in New York City. J HIV/AIDS Soc Serv 2012 Oct;11(4):406-423. [doi: 10.1080/15381501.2012.735166]

15. Torraco RJ. Writing integrative literature reviews: guidelines and examples. Hum Resour Dev Rev 2016 Jul 24;4(3):356-367. [doi: $10.1177 / 1534484305278283$ ]

16. Yorks L. What we know, what we don't know, what we need to know-integrative literature reviews are research. Hum Resour Dev Rev 2008 Jun 01;7(2):139-141. [doi: 10.1177/1534484308316395] 
17. Kemppainen V, Tossavainen K, Turunen H. Nurses' roles in health promotion practice: an integrative review. Health Promot Int 2013 Dec;28(4):490-501. [doi: 10.1093/heapro/das034] [Medline: 22888155]

18. Stormacq C, Van den Broucke S, Wosinski J. Does health literacy mediate the relationship between socioeconomic status and health disparities? Integrative review. Health Promot Int 2019 Oct 01;34(5):1-17. [doi: 10.1093/heapro/day062] [Medline: 30107564$]$

19. Whittemore R, Knafl K. The integrative review: updated methodology. J Adv Nurs 2005 Dec;52(5):546-553. [doi: 10.1111/j.1365-2648.2005.03621.x] [Medline: 16268861]

20. Doty DH, Glick WH. Typologies as a unique form of theory building: toward improved understanding and modeling. Acad Manag Rev 1994 Apr;19(2):230-251. [doi: 10.5465/amr.1994.9410210748]

21. Kaelber DC, Pan EC. The value of personal health record (PHR) systems. AMIA Annu Symp Proc 2008 Nov 06:343-347 [FREE Full text] [Medline: 18999276]

22. Vincent A, Kaelber DC, Kaelber DC, Pan E, Shah S, Shah SS, et al. A patient-centric taxonomy for personal health records (PHRs). AMIA Annu Symp Proc 2008 Nov 06:763-767 [FREE Full text] [Medline: 18998912]

23. Archer N, Fevrier-Thomas U, Lokker C, McKibbon KA, Straus SE. Personal health records: a scoping review. J Am Med Inform Assoc 2011 Jul;18(4):515-522 [FREE Full text] [doi: 10.1136/amiajnl-2011-000105] [Medline: 21672914]

24. Irizarry T, DeVito DA, Curran CR. Patient portals and patient engagement: a state of the science review. J Med Internet Res 2015 Jun;17(6):e148 [FREE Full text] [doi: 10.2196/jmir.4255] [Medline: 26104044]

25. Pushpangadan S, Seckman C. Consumer perspective on personal health records: a review of the literature. Online J Nurs Informatics. URL: https://www.himss.org/resources/consumer-perspective-personal-health-records-review-literature [accessed 2019-06-18]

26. Eysenbach G. Consumer health informatics. Br Med J 2000 Jun 24;320(7251):1713-1716 [FREE Full text] [doi: 10.1136/bmj.320.7251.1713] [Medline: 10864552]

27. Eysenbach G, Jadad AR. Evidence-based patient choice and consumer health informatics in the internet age. J Med Internet Res 2001 Jun;3(2):E19 [FREE Full text] [doi: 10.2196/jmir.3.2.e19] [Medline: 11720961]

28. Jadad A. Consumer health informatics: supporting the hightouch. Ottawa, Canada: Consumer Health Informatics Summit; 2007. URL: http://www.ehealthinformation.ca/wp-content/uploads/2014/07/2007-Consumer-Health-Informatics-Summit. pdf [accessed 2021-04-22]

29. Johnson K, Jimison HB, Mandl KD. Consumer health informatics personal health records. In: Biomedical Informatics. London: Springer; 2013:517-539.

30. Marceglia S, Fontelo P, Ackerman M. Transforming consumer health informatics: connecting CHI applications to the health-IT ecosystem. J Am Med Inform Assoc 2015 Apr;22(e1):210-212 [FREE Full text] [doi: 10.1093/jamia/ocu030] [Medline: 25665702]

31. Americans want benefits of personal health records. Markle. 2003. URL: https://www.markle.org/publications/ 950-americans-want-benefits-personal-health-records [accessed 2021-04-22]

32. Tang PC, Ash JS, Bates DW, Overhage JM, Sands DZ. Personal health records: definitions, benefits, and strategies for overcoming barriers to adoption. J Am Med Inform Assoc 2006 Mar;13(2):121-126 [FREE Full text] [doi: 10.1197/jamia.M2025] [Medline: 16357345]

33. Garrett P, Seidman J. EMR vs EHR? What is the Difference? Health IT Buzz. 2011. URL: https://www.healthit.gov/ buzz-blog/electronic-health-and-medical-records/emr-vs-ehr-difference [accessed 2019-06-18]

34. Raisinghani MS, Young E. Personal health records: key adoption issues and implications for management. Int J Electron Healthc 2008;4(1):67. [doi: 10.1504/ijeh.2008.018921]

35. Hodge T, Giokas D. EMR, EHR and PHR? Why all the confusion? Canada Health Infoway. 2011. URL: https://www. infoway-inforoute.ca/en/what-we-do/blog/digital-health-records/6852-emr-ehr-and-phr-why-all-the-confusion [accessed 2019-06-18]

36. Silow-Carroll S, Edwards JN, Rodin D. Using electronic health records to improve quality and efficiency: the experiences of leading hospitals. Issue Brief (Commonw Fund) 2012 Jul;17:1-40. [Medline: 22826903]

37. Detmer D, Bloomrosen M, Raymond B, Tang P. Integrated personal health records: transformative tools for consumer-centric care. BMC Med Inform Decis Mak 2008 Oct 06;8:45 [FREE Full text] [doi: 10.1186/1472-6947-8-45] [Medline: 18837999]

38. Kern J, Fister K, Polasek O. Active patient role in recording health data. In: Encyclopedia of Information Science and Technology, Second Edition. Hershey, Pennsylvania, United States: IGI Global; 2009:14-19.

39. Hoerbst A, Kohl CD, Knaup P, Ammenwerth E. Attitudes and behaviors related to the introduction of electronic health records among Austrian and German citizens. Int J Med Inform 2010 Feb;79(2):81-89. [doi: 10.1016/j.ijmedinf.2009.11.002] [Medline: 20031482]

40. Mon DT, EHR Work Group. HL7 PHR system functional model. In Healthcare Information Management Systems Society (HIMSS) Conference, New Orleans, LA, USA. 2013. URL: https://www.hl7.org/documentcenter/public/calendarofevents/ himss/2013/Personal\%20Health\%20Record\%20System\%20Functional\%20Model.pdf [accessed 2019-06-18]

41. PHR-S FM Personal Health Record System Functional Model (PHR-S FM). Health Level Seven International. URL: https:/ /www.h17.org/implement/standards/product_brief.cfm?product_id=88 [accessed 2019-06-18] 
42. Endsley S, Kibbe DC, Linares A, Colorafi K. An introduction to personal health records. Fam Pract Manag 2006 May;13(5):57-62 [FREE Full text] [Medline: 16736906]

43. Anoshiravani A, Gaskin G, Kopetsky E, Sandborg C, Longhurst CA. Implementing an Interoperable Personal Health Record in Pediatrics: Lessons Learned at an Academic Children's Hospital. J Particip Med 2011 Jul 10;3:- [FREE Full text] [Medline: 21853160]

44. Gaskin GL, Longhurst C, Slayton R, Das A. Sociotechnical challenges of developing an interoperable personal health record. Appl Clin Inform 2017 Dec 16;02(04):406-419. [doi: 10.4338/aci-2011-06-ra-0035]

45. Barbarito F, Pinciroli F, Barone A, Pizzo F, Ranza R, Mason J, et al. Implementing the lifelong personal health record in a regionalised health information system: the case of Lombardy, Italy. Comput Biol Med 2015 Apr;59:164-174. [doi: 10.1016/j.compbiomed.2013.10.021] [Medline: 24238969]

46. Kikuchi S, Sachdeva S, Bhalla S. Cloud computing based PHR architecture using multi layers model. J Softw Eng Appl 2012;05(11):903-911. [doi: 10.4236/jsea.2012.531105]

47. Kim MI, Johnson K. Personal health records: evaluation of functionality and utility. J Am Med Inform Assoc 2002;9(2):171-180 [FREE Full text] [doi: 10.1197/jamia.m0978] [Medline: 11861632]

48. Cabitza F, Simone C, De Michelis G. User-driven prioritization of features for a prospective interpersonal health record: perceptions from the Italian context. Comput Biol Med 2015 Apr;59:202-210. [doi: 10.1016/j.compbiomed.2014.03.009] [Medline: 24768267]

49. Bachiri M, Idri A, Fernández-Alemán JL, Toval A. Mobile personal health records for pregnancy monitoring functionalities: analysis and potential. Comput Methods Programs Biomed 2016 Oct;134:121-135. [doi: 10.1016/j.cmpb.2016.06.008] [Medline: 27480737]

50. Emani S, Yamin CK, Peters E, Karson AS, Lipsitz SR, Wald JS, et al. Patient perceptions of a personal health record: a test of the diffusion of innovation model. J Med Internet Res 2012 Nov;14(6):e150 [FREE Full text] [doi: 10.2196/jmir.2278] [Medline: 23128775]

51. Schnipper JL, Gandhi TK, Wald JS, Grant RW, Poon EG, Volk LA, et al. Effects of an online personal health record on medication accuracy and safety: a cluster-randomized trial. J Am Med Inform Assoc 2012 Sep;19(5):728-734 [FREE Full text] [doi: 10.1136/amiajnl-2011-000723] [Medline: 22556186]

52. Weppner WG, Ralston JD, Koepsell TD, Grothaus LC, Reid RJ, Jordan L, et al. Use of a shared medical record with secure messaging by older patients with diabetes. Diabetes Care 2010 Nov;33(11):2314-2319 [FREE Full text] [doi: 10.2337/dc10-1124] [Medline: 20739686]

53. Tom JO, Mangione-Smith R, Solomon C, Grossman DC. Integrated personal health record use: association with parent-reported care experiences. Pediatrics 2012 Jul 11;130(1):183-190. [doi: 10.1542/peds.2011-1786] [Medline: 22689872]

54. Islam R, Kikuchi K, Sato Y, Izukura R, Yokota F, Nishikitani M, et al. Personal Health Record (PHR) system in portable health clinic. Stud Health Technol Inform 2020 Jun 16;270:1347-1348. [doi: 10.3233/SHTI200435] [Medline: 32570652]

55. Heart T, Ben-Assuli O, Shabtai I. A review of PHR, EMR and EHR integration: a more personalized healthcare and public health policy. Health Policy Technol 2017 Mar;6(1):20-25. [doi: 10.1016/j.hlpt.2016.08.002]

56. Seo D, Park YR, Lee Y, Kim JY, Park J, Lee J. The use of mobile personal health records for hemoglobin A1c regulation in patients with diabetes: retrospective observational study. J Med Internet Res 2020 Jun 02;22(6):e15372 [FREE Full text] [doi: 10.2196/15372] [Medline: 32484447]

57. Kipping S, Stuckey MI, Hernandez A, Nguyen T, Riahi S. A web-based patient portal for mental health care: benefits evaluation. J Med Internet Res 2016 Nov 16;18(11):e294 [FREE Full text] [doi: 10.2196/jmir.6483] [Medline: 27852556]

58. Kibbe DC, Phillips RL, Green LA. The continuity of care record. Am Fam Physician 2004 Oct 01;70(7):1220, 2-1220, 3 [FREE Full text] [Medline: 15508532]

59. Folker G. The chronic need for connectivity: helping today's aging heath care consumers help themselves. Consumer Health Informatics Summit. Ottawa, Canada: Consumer Health Informatics Summit; 2007. URL: http://www.ehealthinformation.ca/ wp-content/uploads/2014/07/2007-Consumer-Health-Informatics-Summit.pdf [accessed 2021-04-22]

60. Ralston JD, Carrell D, Reid R, Anderson M, Moran M, Hereford J. Patient web services integrated with a shared medical record: patient use and satisfaction. J Am Med Inform Assoc 2007 Nov;14(6):798-806 [FREE Full text] [doi: 10.1197/jamia.M2302] [Medline: 17712090]

61. Kim J, Ryu B, Cho S, Heo E, Kim Y, Lee J, et al. Impact of personal health records and wearables on health outcomes and patient response: three-arm randomized controlled trial. JMIR Mhealth Uhealth 2019 Jan 04;7(1):e12070 [FREE Full text] [doi: 10.2196/12070] [Medline: 30609978]

62. Slevin P, Caulfield B. Patient-generated health data: looking toward future health care. In: Wearable Technology in Medicine and Health Care. Amsterdam: Elsevier; 2018:261-273.

63. Ball MJ, Smith C, Bakalar RS. Personal health records: empowering consumers. J Healthc Inf Manag 2007;21(1):76-86. [Medline: 17299929]

64. Mercer JG. Using web based tools to help patients achieve optimal clinical outcomes. Consumer Health Informatics Summit. Ottawa, Canada: Consumer Health Informatics Summit; 2007. URL: http://www.ehealthinformation.ca/wp-content/uploads/ 2014/07/2007-Consumer-Health-Informatics-Summit.pdf [accessed 2021-04-22] 
65. Terry M. The personal health dashboard: consumer electronics is growing in the health and wellness market. Telemed J E Health 2009 Sep;15(7):642-645. [doi: 10.1089/tmj.2009.9947] [Medline: 19747072]

66. Hefner JL, MacEwan SR, Biltz A, Sieck CJ. Patient portal messaging for care coordination: a qualitative study of perspectives of experienced users with chronic conditions. BMC Fam Pract 2019 May 03;20(1):57 [FREE Full text] [doi: 10.1186/s12875-019-0948-1] [Medline: 31053063]

67. Plate JF, Ryan SP, Bergen MA, Hong CS, Attarian DE, Seyler TM. Utilization of an Electronic Patient Portal Following Total Joint Arthroplasty Does Not Decrease Readmissions. J Arthroplasty 2019 Feb;34(2):211-214. [doi: 10.1016/j.arth.2018.11.002] [Medline: 30497899]

68. Hill JN, Smith BM, Weaver FM, Nazi KM, Thomas FP, Goldstein B, et al. Potential of personal health record portals in the care of individuals with spinal cord injuries and disorders: provider perspectives. J Spinal Cord Med 2018 May 21;41(3):298-308 [FREE Full text] [doi: 10.1080/10790268.2017.1293760] [Medline: 28325112]

69. Kai E, Ahmed A. Technical challenges in providing remote health consultancy services for the unreached community. In: Proceedings of the 27th International Conference on Advanced Information Networking and Applications Workshops. 2013 Presented at: 27th International Conference on Advanced Information Networking and Applications Workshops; March 25-28, 2013; Barcelona, Spain p. 1016-1020. [doi: 10.1109/waina.2013.227]

70. Halamka JD, Mandl KD, Tang PC. Early experiences with personal health records. J Am Med Inform Assoc 2008 Jan;15(1):1-7 [FREE Full text] [doi: 10.1197/jamia.M2562] [Medline: 17947615]

71. Frost JH, Massagli MP. Social uses of personal health information within PatientsLikeMe, an online patient community: what can happen when patients have access to one another's data. J Med Internet Res 2008;10(3):e15 [FREE Full text] [doi: 10.2196/jmir.1053] [Medline: 18504244]

72. Bickmore TW, Schulman D, Sidner CL. A reusable framework for health counseling dialogue systems based on a behavioral medicine ontology. J Biomed Inform 2011 Apr;44(2):183-197 [FREE Full text] [doi: 10.1016/j.jbi.2010.12.006] [Medline: 21220044]

73. Goodman K. Decision support the personal health record. URL: http://www.projecthealthdesign.org/media/file/ ELSI-decision-support.pdf [accessed 2019-06-18]

74. Davis S, MacKay L. Moving beyond the rhetoric of shared decision-making: designing personal health record technology with young adults with Type 1 diabetes. Can J Diabetes 2020 Jul;44(5):434-441. [doi: 10.1016/j.jcjd.2020.03.009] [Medline: 32616277]

75. Schera F, Schäfer M, Bucur A, van Leeuwen J, Ngantchjon EH, Graf N, et al. iManageMyHealth and iSupportMyPatients: mobile decision support and health management apps for cancer patients and their doctors. Ecancermedicalscience 2018 Jul 11;12:848 [FREE Full text] [doi: 10.3332/ecancer.2018.848] [Medline: 30079110]

76. Bateja R, Dubey S, Bhatt A. A patient-centric healthcare model based on health recommender systems. In: Recent Findings in Intelligent Computing Techniques. Singapore: Springer; 2018:269-276.

77. Sequist TD, Zaslavsky AM, Colditz GA, Ayanian JZ. Electronic patient messages to promote colorectal cancer screening: a randomized controlled trial. Arch Intern Med 2011 Apr 11;171(7):636-641 [FREE Full text] [doi: 10.1001/archinternmed.2010.467] [Medline: 21149743]

78. Sykes TA, Venkatesh V, Johnson JL. Enterprise system implementation and employee job performance: understanding the role of advice networks. MIS Q 2014 Jan 1;38(1):51-72. [doi: 10.25300/misq/2014/38.1.03]

79. Grant RW, Wald JS, Schnipper JL, Gandhi TK, Poon EG, Orav EJ, et al. Practice-linked online personal health records for type 2 diabetes mellitus: a randomized controlled trial. Arch Intern Med 2008 Sep 08;168(16):1776-1782 [FREE Full text] [doi: 10.1001/archinte.168.16.1776] [Medline: 18779465]

80. Krist AH, Woolf SH, Bello GA, Sabo RT, Longo DR, Kashiri P, et al. Engaging primary care patients to use a patient-centered personal health record. Ann Fam Med 2014 Sep;12(5):418-426 [FREE Full text] [doi: 10.1370/afm.1691] [Medline: 25354405]

81. Porter ME, Teisberg EO. Redefining health care: creating value-based competition on results. National Association of Chain Drug Stores. 2006. URL: https://www.hbs.edu/ris/Publication\%20Files/ 20060502\%20NACDS\%20-\%20Final\%2005012006\%20for\%200n\%20Point db5ede1d-3d06-41f0-85e3-c11658534a63. pdf [accessed 2021-04-22]

82. Porter ME. Value-based health care delivery. Ann Surg 2008 Oct;248(4):503-509. [doi: 10.1097/SLA.0b013e31818a43af] [Medline: 18936561$]$

83. Nazi KM. The personal health record paradox: health care professionals' perspectives and the information ecology of personal health record systems in organizational and clinical settings. J Med Internet Res 2013 Apr;15(4):e70 [FREE Full text] [doi: 10.2196/jmir.2443] [Medline: 23557596]

84. Porter ME. What is value in health care? N Engl J Med 2010 Dec 23;363(26):2477-2481. [doi: 10.1056/nejmp1011024]

85. Hess R, Bryce CL, Paone S, Fischer G, McTigue KM, Olshansky E, et al. Exploring challenges and potentials of personal health records in diabetes self-management: implementation and initial assessment. Telemed J E Health 2007

Oct;13(5):509-517. [doi: 10.1089/tmj.2006.0089] [Medline: 17999613] 
86. Wang CK. Security and privacy of personal health record, electronic medical record and health information. Probl Perspect Manag. 2015. URL: https://businessperspectives.org/images/pdf/applications/publishing/templates/article/assets/6962/ PPM 201504 Wang.pdf [accessed 2019-06-18]

87. Zulman DM, Nazi KM, Turvey CL, Wagner TH, Woods SS, An LC. Patient interest in sharing personal health record information: a web-based survey. Ann Intern Med 2011 Dec 20;155(12):805-810. [doi:

10.7326/0003-4819-155-12-201112200-00002] [Medline: 22184687]

88. Williams JB, Weber-Jahnke JH. The regulation of personal health records in Canada. Can J Law Technol. URL: https://ojs. library.dal.ca/CJLT/article/download/4944/4452 [accessed 2019-06-18]

89. Manard W, Scherrer JF, Salas J, Schneider FD. Patient portal use and blood pressure control in newly diagnosed hypertension. J Am Board Fam Med 2016 Jul;29(4):452-459 [FREE Full text] [doi: 10.3122/jabfm.2016.04.160008] [Medline: 27390376]

90. Rothman B, Leonard JC, Vigoda MM. Future of electronic health records: implications for decision support. Mt Sinai J Med 2012 Dec 13;79(6):757-768. [doi: 10.1002/msj.21351] [Medline: 23239213]

91. Hess R. The diabetes patient portal: patient perspectives on structure and delivery. Diabetes Spectrum 2006 Apr 01;19(2):106-110. [doi: 10.2337/diaspect.19.2.106]

92. King DK, Toobert DJ, Portz JD, Strycker LA, Doty A, Martin C, et al. What patients want: relevant health information technology for diabetes self-management. Health Technol 2012 Mar 5;2(3):147-157. [doi: 10.1007/s12553-012-0022-7]

93. Winkelman WJ. Patient-perceived usefulness of online electronic medical records: employing grounded theory in the development of information and communication technologies for use by patients living with chronic illness. J Am Med Informatics Assoc 2005 Jan 31;12(3):306-314. [doi: 10.1197/jamia.m1712]

94. Agarwal R, Anderson C, Zarate J, Ward C. If we offer it, will they accept? Factors affecting patient use intentions of personal health records and secure messaging. J Med Internet Res 2013 Feb;15(2):e43 [FREE Full text] [doi: 10.2196/jmir.2243] [Medline: 23470453]

95. Rizk S. Utility of a comprehensive Personal Health Record (PHR) strategy. Qatar Foundation Annual Research Forum Proceedings 2013 Nov(2013):ICTO 011. [doi: 10.5339/qfarf.2013.ICTO-011]

96. Dorland's Medical Dictionary Online. URL: https://www.dorlandsonline.com/dorland/home [accessed 2021-04-22]

97. Burns LR. The business of healthcare innovation in the Wharton school curriculum. The Business of Healthcare Innovation 2012:1-24. [doi: 10.1017/CBO9781139176620.001]

98. Martineau M. The internet changes everything: Lessons from other industries. Ottawa, Canada: Consumer Health Informatics Summit; 2007. URL: http://www.ehealthinformation.ca/wp-content/uploads/2014/07/2007-Consumer-Health-InformaticsSummit.pdf [accessed 2021-04-22]

99. Ross SE, Moore LA, Earnest MA, Wittevrongel L, Lin C. Providing a web-based online medical record with electronic communication capabilities to patients with congestive heart failure: randomized trial. J Med Internet Res 2004 May 14;6(2):e12 [FREE Full text] [doi: 10.2196/jmir.6.2.e12] [Medline: 15249261$]$

100. Faisal S, Blandford A, Potts HW. Making sense of personal health information: challenges for information visualization. Health Informatics J 2013 Sep;19(3):198-217. [doi: 10.1177/1460458212465213] [Medline: 23981395]

101. McDaniel AM, Schutte DL, Keller LO. Consumer health informatics: from genomics to population health. Nurs Outlook 2008 Sep;56(5):216-223. [doi: 10.1016/j.outlook.2008.06.006] [Medline: 18922271]

102. Brennan PF, Downs S, Casper G. Project HealthDesign: rethinking the power and potential of personal health records. J Biomed Inform 2010 Oct;43(5 Suppl):S3-S5 [FREE Full text] [doi: 10.1016/j.jbi.2010.09.001] [Medline: 20937482]

103. Demiris G, Afrin LB, Speedie S, Courtney KL, Sondhi M, Vimarlund V, et al. Patient-centered applications: use of information technology to promote disease management and wellness. A white paper by the AMIA knowledge in motion working group. J Am Med Inform Assoc 2008 Jan;15(1):8-13 [FREE Full text] [doi: 10.1197/jamia.M2492] [Medline: 17947617]

104. Williams J, Weber-Jahnke J. Regulation of patient management software. Health Law J 2010;18:73-111. [Medline: 22125972]

105. Hassol A, Walker JM, Kidder D, Rokita K, Young D, Pierdon S, et al. Patient experiences and attitudes about access to a patient electronic health care record and linked web messaging. J Am Med Inform Assoc 2004 Nov;11(6):505-513 [FREE Full text] [doi: 10.1197/jamia.M1593] [Medline: $\underline{15299001]}$

106. Bates DW, Bitton A. The future of health information technology in the patient-centered medical home. Health Aff (Millwood) 2010 Apr;29(4):614-621. [doi: 10.1377/hlthaff.2010.0007] [Medline: 20368590]

107. AbuOun NA, Abdel-Hamid A, El-Nasr MA. The concept of a medical information system by rate of use (CHEBHOSP). Heal Informatics Int J 2015 May 31;4(1/2):1-11. [doi: 10.5121/hiij.2015.4201]

108. Studeny J, Coustasse A. Personal health records: is rapid adoption hindering interoperability? Perspect Health Inf Manag 2014;11:1e [FREE Full text] [Medline: 25214822]

109. AbuOun NA, Abdel-Hamid A, El-Nasr MA. A novel framework for electronic global health record access. Health Informatic Int J. 2015 May 31. URL: http://www.airccse.org/journal/hiij/papers/4215hiij01.pdf [accessed 2021-04-26]

110. Walker J, Pan E, Johnston D, Adler-Milstein J, Bates DW, Middleton B. The value of health care information exchange and interoperability. Health Aff (Millwood) 2005 Jan;Suppl Web Exclusives:5-10. [doi: 10.1377/hlthaff.w5.10] [Medline: 15659453] 
111. Wuerdeman L, Volk L, Pizziferri L, Tsurikova R, Harris C, Feygin R, et al. How accurate is information that patients contribute to their Electronic Health Record? AMIA Annu Symp Proc 2005:834-838 [FREE Full text] [Medline: 16779157]

112. Nippak PM, Isaac WW, Geertsen A, Ikeda-Douglas CJ. Family attitudes towards an electronic personal health record in a long term care facility. J Hosp Adm 2015 Mar 22;4(3):9. [doi: 10.5430/jha.v4n3p9]

113. Veronin M. Enhancing personal health record adoption through the community pharmacy network: a service project. Innov Pharm 2015 Jan 01;6(4):-. [doi: 10.24926/iip.v6i4.403]

114. Bates DW, Wells S. Personal health records and health care utilization. J Am Med Assoc 2012 Nov 21;308(19):2034-2036. [doi: 10.1001/jama.2012.68169] [Medline: 23168828]

115. Fricton JR, Davies D. Personal health records to improve health information exchange and patient safety. In: Advances in Patient Safety: New Directions and Alternative Approaches (Vol. 4: Technology and Medication Safety). Bethesda MD, USA: National Center for Biotechnology Information, U.S. National Library of Medicine; 2008:1-10.

116. Menon AS, Greenwald S, Ma TJ, Kooshesh S, Duriseti R. Patient and physician willingness to use personal health records in the emergency department. West J Emerg Med 2012 May 1;13(2):172-175 [FREE Full text] [doi: 10.5811/westjem.2011.11.6844] [Medline: 22900108]

117. Cavoukian A, Rossos PG. Personal Health Information: A Practical Tool for Physicians Transitioning from Paper-Based Records to Electronic Health Records. Ontario, Canada: Information and Privacy Commissioner of Ontario; 2009. URL: https://www.ipc.on.ca/wp-content/uploads/Resources/phipa-toolforphysicians.pdf [accessed 2019-06-18]

118. Garrido T, Kanter M, Meng D, Turley M, Wang J, Sue V, et al. Race/ethnicity, personal health record access, and quality of care. Am J Manag Care 2015 Feb 01;21(2):103-113 [FREE Full text] [Medline: 25880485]

119. Weitzman ER, Kelemen S, Kaci L, Mandl KD. Willingness to share personal health record data for care improvement and public health: a survey of experienced personal health record users. BMC Med Inform Decis Mak 2012 May 22;12:39 [FREE Full text] [doi: 10.1186/1472-6947-12-39] [Medline: 22616619]

120. Bouri N, Ravi S. Going mobile: how mobile personal health records can improve health care during emergencies. JMIR Mhealth Uhealth 2014 Mar;2(1):e8 [FREE Full text] [doi: 10.2196/mhealth.3017] [Medline: 25098942]

121. Tomines A, Readhead H, Readhead A, Teutsch S. EGEMS (Wash DC) 2013 Oct 28;1(2):1019 [FREE Full text] [doi: 10.13063/2327-9214.1019] [Medline: 25848571]

122. Kostadinovska A, de Vries GJ, Geleijnse G, Zdravkova K. Employing personal health records for population health management. In: ICT Innovations 2014. Switzerland: Springer International Publishing; 2015:65-74.

123. Caligtan CA, Dykes PC. Electronic health records and personal health records. Semin Oncol Nurs 2011 Aug;27(3):218-228. [doi: 10.1016/j.soncn.2011.04.007] [Medline: 21783013]

124. Garvin J, Odom-Wesley B, Rudman WJ, Stewart RS. Healthcare disparities and the role of personal health records. The American Health Information Management Association. 2009. URL: https://library.ahima.org/doc?oid=91677\#.YIEv5-gzayI [accessed 2021-04-22]

125. Gysels M, Richardson A, Higginson IJ. Does the patient-held record improve continuity and related outcomes in cancer care: a systematic review. Health Expect 2007 Mar;10(1):75-91 [FREE Full text] [doi: 10.1111/j.1369-7625.2006.00415.x] [Medline: 17324196 ]
Abbreviations
CDS: clinical decision support
CDVC: care delivery value chain
EHR: electronic health record
EMR: electronic medical record
HIS: health information system
HIT: health information technology
PHI: personal health information
PHR: personal health record
PMRI: patient medical record information

Edited by G Eysenbach; submitted 31.12.20; peer-reviewed by HL Patterson, S Riahi; comments to author 25.01.21; revised version
received 30.01.21; accepted 15.04.21; published 29.04.21
Please cite as:
Ruhi U, Chugh R
Utility, Value, and Benefits of Contemporary Personal Health Records: Integrative Review and Conceptual Synthesis
J Med Internet Res 2021;23(4):e26877
URL: $\underline{\text { https://www.jmir.org/2021/4/e26877 }}$
doi: $\underline{10.2196 / 26877}$
PMID: $\underline{33866308}$
(page number not for citation purposes) 
(CUmar Ruhi, Ritesh Chugh. Originally published in the Journal of Medical Internet Research (https://www.jmir.org), 29.04.2021. This is an open-access article distributed under the terms of the Creative Commons Attribution License (https://creativecommons.org/licenses/by/4.0/), which permits unrestricted use, distribution, and reproduction in any medium, provided the original work, first published in the Journal of Medical Internet Research, is properly cited. The complete bibliographic information, a link to the original publication on https://www.jmir.org/, as well as this copyright and license information must be included. 